\title{
IN A UNIVERSITY HOSPITAL OF BUENOS AIRES CITY
}

\section{Fernández Norma ${ }^{1}$, Canteros Cristina ${ }^{2}$,Farías Luciana ${ }^{1}$,Toranzo Adriana ${ }^{2}$,Tiraboschi INora ${ }^{1}$,Stecher Daniel ${ }^{1}$ \\ ${ }^{1}$ Infectious Disease Division. Hospital de Clínicas "José de San Martín".Universidad de Buenos Aires \\ 2 INEI- ANLIS “Dr. C G Malbrán” \\ Buenos Aires. Argentina}

Introduction

Paracoccidioidomycosis (PCM) is a systemic and endemic fungal disease that is restricted to Latin America.

In Argentina,the endemic area is located north of the 34옹 parallel.

Objective

To report cases of PCM treated in a University Hospital in the city of Buenos Aires, Argentina.

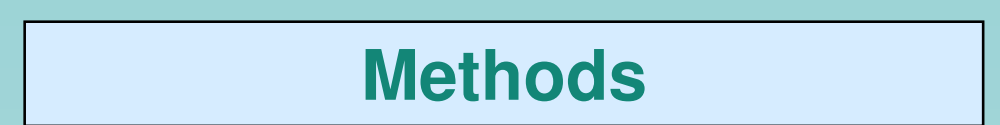

Retrospective study .Source documents were medical records from patients with PCM diagnosed from 2002 to 2017.

\section{Results}

All patients $(n=22)$ were adult men.Mean age 53 yrs old (range 29-72).

All patients received Itraconazole $100-400 \mathrm{mg} /$ day. Favourable outcome $12 / 18(66 \%)$ cases.
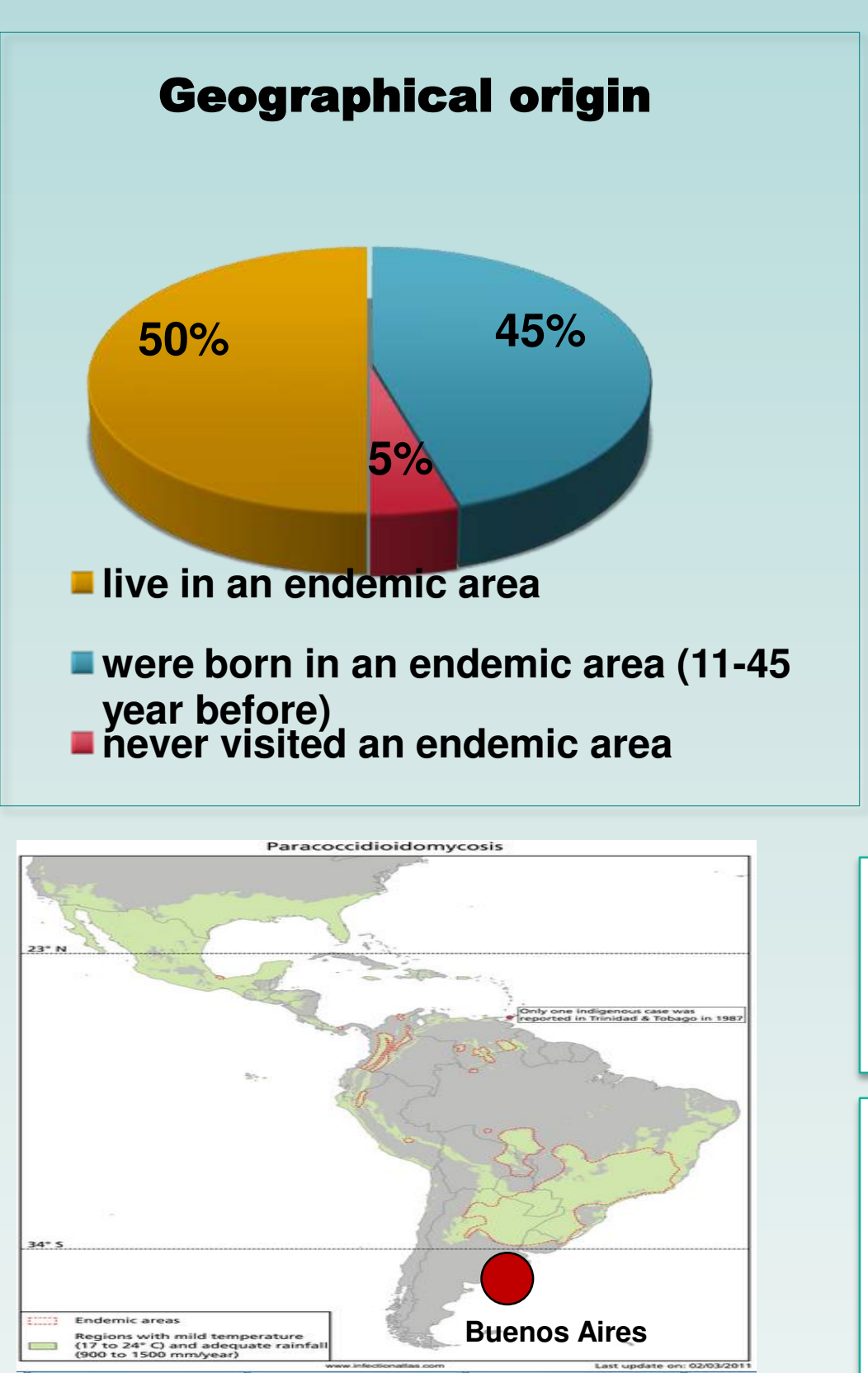

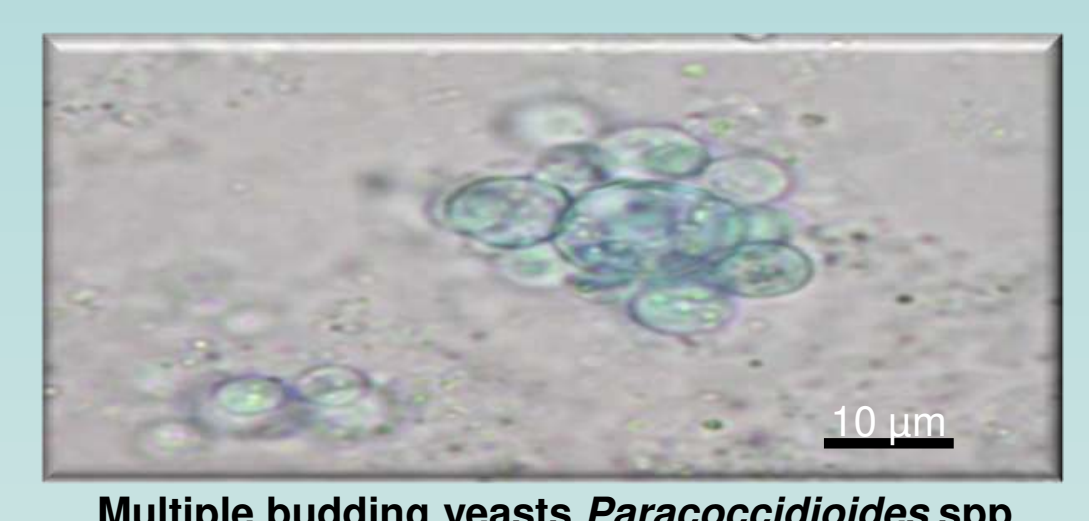

Multiple budding yeasts Paracoccidioides spp $400 \mathrm{X}$

Fresh direct examination of specimen

(DE) $\quad 72.7 \% \quad 16 / 22$

Culture positive $\quad 3 / 22$

\begin{tabular}{|c|c|}
\hline $\begin{array}{l}\text { Antibodies anti-Paracoccidioides } \\
\text { immunodifussion (PbA-ID) + DE } \\
\text { Only Positive PbA-ID }\end{array}$ & $\begin{array}{l}54 \%(12 / 22) \\
22 \% \quad(5 / 22)\end{array}$ \\
\hline $\begin{array}{c}\text { 2015-2018 } \\
\text { Last six cases } \\
\text { Nested PCR (Bialek et a } \\
\text { Samples: sputum, biops } \\
\text { glands larynx, vocal cords, o } \\
\text { Nested PCR GP43 } \\
\text { Nested PCR GP43 + D } \\
\text { Nested PCR GP43 + Pk }\end{array}$ & $\begin{array}{l}\text { 2000) } \\
\text { es adrenal } \\
\text { al mucosa. } \\
6 / 6 \\
5 / 6 \\
\text { A-ID } 3 / 6\end{array}$ \\
\hline Conclusions & \\
\hline
\end{tabular}

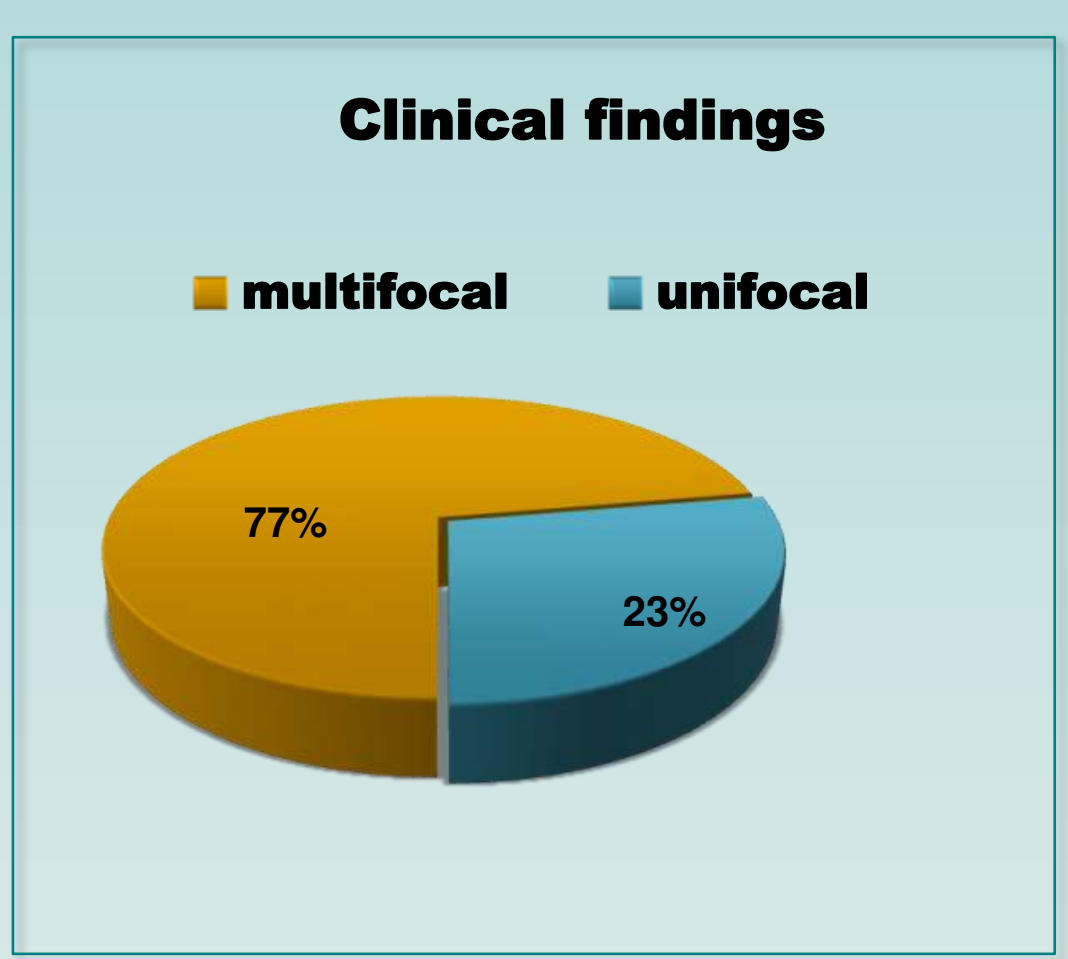

Clinical findings $\mathrm{N}=22$

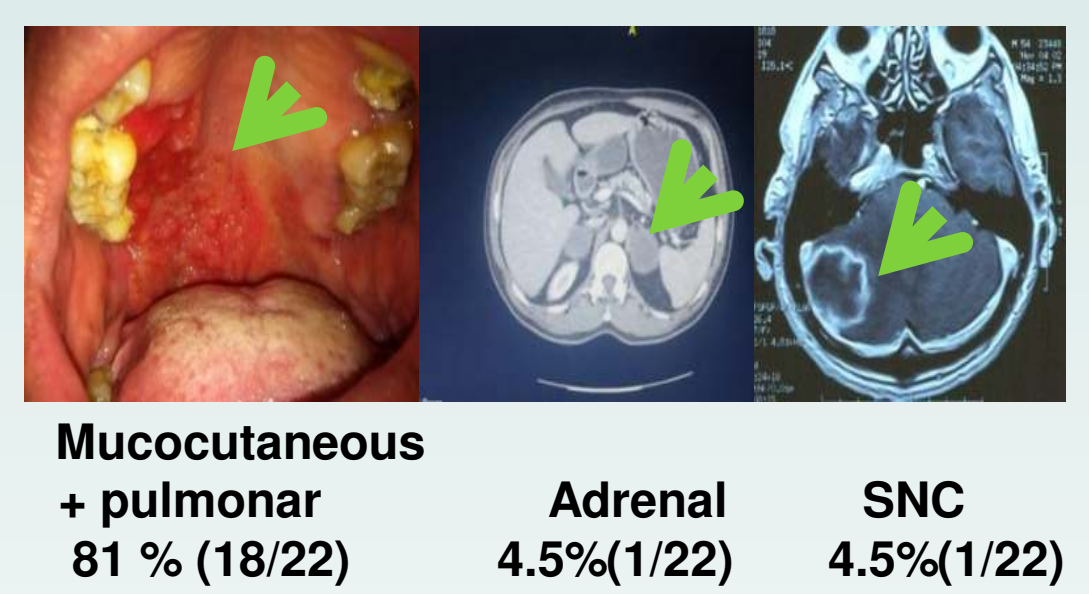

Buenos Aires City records few PCM cases; however, the large number of migrants from Argentina's northern provinces and neighboring countries, where PCM is endemic, should be an alert for its diagnosis.

The detection of one patients who did not visit or lived in the endemic area could be associated with a displacement of the fungus to new areas due to global climate change.

Mucocutaneous and pulmonar lesions are more frequent in clinical findings ( $81 \%)$.

Clinical suspicion and direct examination (72.7\%) are mandatory in patients who inhabit or inhabited the PCM endemic area. Serological test is also an important tool in diagnostic(54\%) and sometimes, the only evidence of this mycosis (22\%). Culture has low sensitivity.

It is also important to include the differential diagnosis with pathogens that share ecological and physiopathological similarities with PCM. 